\title{
Study of the Strategies and Necessity of the Infiltration of Traditional Culture Education in Art Design Major of Colleges and Universities
}

\author{
Li Meiyue \\ JiLin business and technology college, China \\ Li Meiyue@163.com
}

Key Words: Art Design, Traditional Culture, Education of Colleges

\begin{abstract}
Through analyzing the deficiencies of mastering Chinese traditional culture's spirit and the negative influence of art design due to accumulate professional acknowledges not enough for students of art design major in the current time, this paper aims to emphasize the necessity of the infiltration of traditional culture education in art design major, find out the effective infiltration methods and ways of traditional cultural elements in art and design teaching.
\end{abstract}

\section{Introduction}

Culture is a symbol of national social ideology, and it is the crystallization of people's material and cultural spirit. Chinese traditional culture is characterized with our race; it is the foundation of the continuousdevelopment of Chinese nation, and mix with Chinese nation's spirit style. Art worldobtains many fruitful results in the nourishment of Chinese traditional culture from the ancient to the present, which are the essence of Chinese traditional culture, is the Chinese nation endless fundamental forces. And the penetration of Chinese traditional culture is an effective way to study art.The connection between art and traditional culture thoughts will show in the works, enable to cultivate students' sentiment, enhance their cultural literacy, so as to enhance the value of art itself.

With the rapid development of economic and culture of our country and the deepening exchange of China and other countries, foreign culture are affecting all aspects of our life with each passing day, especially for young people. As far as students of art design major are concerned, the application involved in Chinese traditional culture at present is not flexible enough to use. Therefore, this paper puts forward it is so necessary thatChinese traditional culture interoperates into the art design education of colleges and universities, and proposes the methods and ways to solve problems.

\section{The Necessity of the Infiltration of Traditional Culture Education in Art Design Major}

When the professional design students do design projectsinvolves the content of Chinese traditional culture, only a few students can have a better understanding of the design contents and design objectives, also can look for relevant literatures and materials actively, also can do some market researches, so that the performances of productsare in good.

However, quite a few students are not good at grasping the spirit of Chinese traditional culture and accumulating cultural elements, often present superficial understanding, thereby the works designed by them is superficial, unmeaning, no substantive content reflects[1]. The main reasonsresulted in the situation are, one is that culture sense of belonging is weak. Cultural sense of belonging is a sense of identity accepts a certain degree of influence in the cultural atmosphere after the accumulation of national and national cultural identity. And the current situation is most of young people's understandingof the culture of our nation are weak increasingly, especially the understanding of traditional Chinese culture,due to the impact of foreign culture. The popular culture from Europe and the United States, idol episodes from South Korea, ACG culture from Japan arethe popular trend focused by most of young people in the present, and are the objects keen to chase by them.Although multi culture have help young people broaden their horizons, dilute the role of Chinese traditional Chinese culture in the young people's thoughts gradually. Part of 
professional art design students, there are a sense of drift when they begin to design their works, always presents kinds of conditions like going through the motions and ambiguous. The other one is, the design techniques are mostly imitated, as well as simple to apply design elements. Since the beginning of the 1990s, a group of designers appliedthe symbol and marks of Chinese traditional culture in the ultimate way to the sign, posters, packaging design projects, shows the far-reaching charm of traditional culture embodied. That played a important role of the re-flourished development of Chinese traditional culture in the design domain. From then on there is a trend that elements of traditional Chinese culture are designed as the main topic in professional art design area, everyone treats "traditional" as the object, but the worksdesigned by students becomes a mere formality mostly. This presents in two aspects mainly, On the one hand is imitating the design technique used. Students in the process of learning design would be impressed with some excellent design works practically, also admit to think in a certain mode easily so as to design many similar works among them. These works are very mechanical, lack of personality and can be found out certain traces of some of the fabulous works. It is difficult to formulate their unique stylesin the way of using the techniques withoutunderstanding and mastering. On the other hand, apply design elements simply. This problem is mainly that students understand the design theme is not in right place, while only know the design elements is traditional, but did not understand the source, relevance, meaning and so on, prevents from excavating the connotation of the essence deeply, just uses the elements and posts them in the images directly [2]. However, excellent designers not only have extraordinary design skills, but also have the experiences of understanding and analysis about the design contents and the accomplishment as professional designer more importantly, and have attention on the market tendency. If involved in designing the contents and elements of Chinese traditional culture, itrequires highly that the designers and their teams should have profound experiences and powerful cultivation of Chinese traditional culture in order to grasp the essences in the application process, and not copy modes of graphics and images superficially.

The creativity of excellent design works comes from the traditional culture and the design idea provided with abundant national characteristics. Nationality is the soul of art design. Modern design is subject to the dual influenced of modern art, modern science and technology. It is impossible to break away from the deep influence of traditional culture on the soil and the foundation of the national culture on which art design depends. Traditional culture chartered with nation, region, society and history influences on people's aesthetic and creative view unconsciously, also impacts on the modern design movement, and affects the vitality of the design works. Some designers ignore the traditional culture, follow the foreign culture and international design work blindly and mechanically, results in the design works of their own does not reflect the cultural heritage of the Chinese nation and the humanities spirit, the works have not exuberant vitality. But based on carrying forward the humanistic spirit some design mastersexcavate, promote and use the traditional art reasonably, combine the international design language, sense of the times and Chinese traditional culture as a matter of course, create Chinese contemporary literary works possess distinctive Chinese flavor with modern sense and have considerable influence in the world.

With the continuous improvement of China's national economy level and the constant enhancement of the national consciousness, understanding the culture of Chinese nation is more and more deep for the people. Especially for professional art design students of colleges and universities, who want to become as the good designers in the future, it is very necessary that integrating Chinese traditional culture into their design works for reflecting the long history of Chinese traditional culture, helps to present the designer's artistic concept, and improve the connotation of the art works.

\section{The Deficiency of the Infiltration of Traditional Culture Education in Art Design Major of Colleges}

Although traditional culture in art design has an important position in art design, and a lot of colleges and universities will also have traditional culture into the teaching of art and design, and the students design many works of art, but there are some problemsstill existed that adding 
traditional culture education on the schedule of art design teaching in Colleges and universities due to various reasons.

The design level of Students is not high. Influenced by the examination-oriented education in our country, art design department ofmany colleges and universities have been restricted, and the most important thing is the low level of design. In the traditional examination-oriented education, students are not very activein the classrooms so as to hinder the students to play their own design abilityseriously. When drawing on the excellent works of art, students can't analyze the advantages and disadvantages of the works, which affect the students' ability of designseriously. With the gradual commercialization of art works, the art design teaching in Colleges and universities must be permeated with traditional culture in order to provide more inspiration and resources for art design.

The Students are lack of understanding of traditional culture. Currently many art design students are less understanding of Chinese traditional culture, which increasesthe difficulty of the penetration of traditional culture in art design teaching in Colleges and universities, and even many of the students when designing the works attach too much importance to the foreign culture and the art, ignoring the extensive and profound Chinese traditional culture. Some students do not have a positive understanding of the importance of traditional culture in the study of art knowledge, which makes it more difficult for teachers. In addition, some teachers do not pay enough attention to the traditional culturein the duration of teaching, and did not teach the knowledge of the traditional culture very well, thus affecting the teaching qualityof traditional culture. Meanwhile, Students are indifferent to the traditional culture, and the opportunities to contact with the traditional culture are less. Many young teachers have not enough attention to this, their own traditional cultural knowledge is not rich enough, can't give the students a good guide. Chinese art in the Ming and Qing Dynasties emerged going backwards, because of the recession of Chinese's national life consciousnessmainly. In the Ming and Qing Dynasties, especially some design works of Qing Dynasty, such as ceramics, embroidery, decoration is very complex and lack of consciousness of life. Today, this phenomenon is still a potential continuation. Some students are indifferent of or have half-baked knowledge about many outstanding design works in traditional cultural elements, even thinking over rarely.

\section{The Methods and ways of the Infiltration of Traditional Culture Education in Art Design Major}

At present, the art design theme is extended from "design and economy" to "design and culture", and plays an important role in the heritage of traditional culture increasingly. How to highlight the traditional culture education in art design education system, promote the students to achieve the integration of traditional culture and modern life in the design, is a hot issue in art design education in the current. The introduction of traditional culture in art design teachingenriches the cultural connotation of the works of art. Only the art works integrated into the traditional cultural can be called the outstanding works of art. Art design as one of the main ways of broadcasting traditional culture, has the responsibility and obligation to promote, and expressof traditional culture adequately in china. Colleges and universities should increase the training level of excellent art design talents; make a certain contribution for the development of cultural undertakings in our country.The infiltration of traditional culture education in art design major, not only are able to let our excellent traditional culture can be inherited, but also enrich the works of art and design. Therefore, it is of great significance to infiltrate the traditional culture in the teaching of art design in Colleges and universities.

In the process of teaching, first of all, teachers should have the high level of mastering the Chinese traditional culture, that means they should be with certain literacy of Chinese traditional culture, enable to analysis cases, interpret the symbol of cultural elements and explain something from multi-prospective in the teaching process, offer correct way of appreciation and thinkingto the students. Secondly, in the design process teachers can guide the students' work, lead students to think from multi angles so as to avoid superficial works. Art design educators have the obligation to 
teach the traditional culture in the classroom, and let the students to learn much more knowledge of the traditional culture of the students at the same time, and lay a good foundation of the development of China's design business for the future. Teachers can teach the students the profound meaning of traditional graphics through the systematic comparison, that is benefit of improving the levels ofmodeling, aesthetics, and leading the students to learn and focus oncultural knowledge such as the folk culture, personal style, art and aesthetics etc.

The professional learning connected with mastering Chinese traditional culture and art theory contents forthe students of design majoris very prominent. Therefore, professional teachers mayfocus on a kind of topics when designing some projects relevant to Chinese traditional culture, for example, "Тао" as the theme, exploring the connotation fully from the literal, abstracting the contents with respect to the traditional culture and art, these contents can be abstract or concrete. When students can collect, understand and analysis the materials relevant to the theme consciously from a similar theme with hands, eyes, brain, they already have detected the origin and development of Chinese culture in learning consciously at the same time. It is helpful to enhance the students' cultivation of Chinese traditional culture and art, accumulateprofessional knowledge.

The students should step out of the classroom, and collectthe first-hand materials and information. The students majoring in art design accumulate the knowledge of Chinese traditional culture and art should not be limited to the contents of books and classrooms, collecting folk songs is a good way to find first-hand data for students in art colleges and universities.There are many relics, and tangible or intangible cultural heritage in China's vast land everywhere, some of artworks was excavated and exhibited, some was be hidden among the people and need to in-depth collection by the method of image data and sketch, written records.

Every student's understanding of the same things will have different views and opinions, the data will be collected for analysis and comparison, even if the same symbol uses in the application for different students will show different visual effects, which is reflected the duration of students learninghow to master the essences through the surface of things deeply and essentially [3].

Furthermore, students stepping out of the classroom are not only close to the folk, but also to the society, can get more practical experiences. Students are able toacquire most of theoretical knowledge more like superficial, abstract, aesthetic things in the classroom, these design cannot stand the test of social practice. That makes students having no ideas about how to work when they start to design a specific project.Andthe projects is difficult to meet the customer's demand, and is out of the practice eventually. Therefore, it is very necessary to encourage students to exercise in practice, which is the way to understand Chinese traditional culture and how to use it in practice.

The students and teachers of art design major should pay attention to the difference between traditional culture and modern culture. With the continuous development of the international trend, the links among the countries strengthen gradually. The nation is the world, the national culture with its unique charm highlights its advantages in the international competition. The effective application of traditional culture in art design education of colleges should be based on equivalent conditions. Valuable cultural heritages of our ancestors left behind combines much more modern elementsin the thousands of years of heritage and promotion, a lot of artworks of traditional culture are given new cultural connotation in the process of succession continuously. Therefore, based on the difference between traditional culture and modern culture, the art design education of colleges should pay attention to innovate and carry forward the traditional culture in the premise of applying the traditional culture effectively, fitting with the contrast from modern art.

The focus of art design teaching is to cultivate students' creative thinking ability. In the market economy environment, the quality of art design works often depends on the cultural aesthetic factors contained in the works. Many Foreign design masters also use a large number of Chinese traditional culture elementsin their works, that is enough to show that Chinese traditional culture has a special creative. Through the combination of tradition and modern culture, we can improve the cultural content and design level of design works as well. Therefore, the combination of traditional culture and modern design concept in the design of teaching is very important to improve the level of students' design. At the same time, the students should realize that the personality 
differences between eastern and Western designs so as to understand the importance of Chinese traditional culture.It is very important for the students to apply creative materials as their pleases andlay a solid foundation of the benign development of the design career in the future. The development of art design in China went through a long and arduous process, and the students now want to get more achievements, they need to redouble their efforts at all.

\section{Summary}

In order to improve the professional art design students' theoretical knowledge and professional standards, it is necessary to enable students to realize the importance of the cognitive understanding of China's traditional culture and art, and great importance of the accumulation of knowledge in action. Only if finding out the potential charm of traditional culture in practice, they are able to design unique outstanding works with Chinese characteristics and the special perspective.

\section{References}

[1]A.H.Jin A.H, Research on the Application Strategies of Traditional Culture in the Art Design Education, Art Identity, 10(2015):55-56(In Chinese)

[2]F.Li, Analysis of Traditional Culture Education for Students of Art major, New West, 7(2013):159(In Chinese)

[3]J.Huang, the Development and Innovation of Art Design Education of Colleges, Art Education, 8(2010):111(In Chinese) 